\title{
IMPOSING STANDARDS
}


A volume in the series

Cornell Studies in Money

Edited by Eric Helleiner and Jonathan Kirshner

A list of titles in this series is available at cornellpress.cornell.edu 


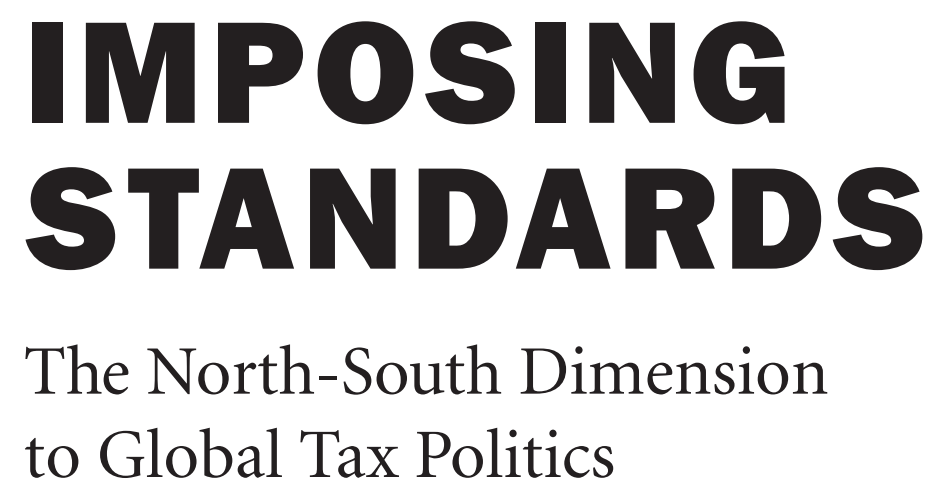

Martin Hearson 
Thanks to generous funding from the Economic and Social Research Council and UK Aid, along with the Bill and Melinda Gates Foundation, the ebook editions of this book are available as open access volumes through the Cornell Open initiative.

\section{Copyright () 2021 by Martin Hearson}

The text of this book is licensed under a Creative Commons Attribution 4.0 International License: https://creativecommons.org/licenses/by/4.0/. To use this book, or parts of this book, in any way not covered by the license, please contact Cornell University Press, Sage House, 512 East State Street, Ithaca, New York 14850. Visit our website at cornellpress.cornell.edu.

First published 2021 by Cornell University Press

Library of Congress Cataloging-in-Publication Data

Names: Hearson, Martin, author.

Title: Imposing standards : the north-south dimension to global tax politics / Martin Hearson.

Description: Ithaca [New York] : Cornell University Press, 2021. | Series: Cornell studies in money | Includes bibliographical references and index.

Identifiers: LCCN 2020038497 (print) | LCCN 2020038498 (ebook) | ISBN 9781501755989 (paperback) | ISBN 9781501756009 (pdf) | ISBN 9781501755996 (epub)

Subjects: LCSH: International business enterprises-Taxation-Developing countries. | Double taxation-Developing countries—Treaties. | Investments, Foreign-Developing countries. | Taxation-Law and legislation-Developing countries. | Globalization-Economic aspects. | Developing countries-Foreign economic relations-Developed countries. | Developed countriesForeign economic relations-Developing countries.

Classification: LCC HD2753 ,H43 2021 (print) | LCC HD2753 (ebook) | DDC 336.2009172/4-dc23

LC record available at https://lccn.loc.gov/2020038497

LC ebook record available at https://lccn.loc.gov/2020038498 